\title{
LA CONDUCTA MOTRIZ: UN NUEVO PARADIGMA PARA LA EDUCACIÓN FÍSICA DEL SIGLO XXI
}

Francisco Lagardera Otero

\section{Resumen}

El texto plantea la necesidad urgente de que la educación física lleve a cabo una auténtica revolución copernicana para que logre ser capaz de desarrollar todo su potencial pedagógico, de acuerdo a las expectativas y necesidades de la sociedad contemporánea. El ser humano funciona como un todo, como un sistema inteligente, de modo que con cada decisión que toma, con cada acción que emprende todo el sistema se pone en funcionamiento: la afectividad, el psiquismo, los órganos, toda la experiencia acumulada..., absolutamente todo el ser. Pierre Parlebas ya desarrolló hace cuatro décadas un concepto que entiende al ser humano como un sistema: la conducta motriz, de modo que cada persona va escribiendo su biografia motriz en la medida que va evolucionando como ser vivo. La educación física aplicando la pedagogía de las conductas motrices puede ser capaz de optimizar, es decir, de mejorar, las conductas motrices de las personas de acuerdo a unos determinados objetivos. Esta y no otra es la auténtica especificidad de la educación física, un gran valor pedagógico y social pues puede ser capaz de ayudar eficazmente a modificar de manera óptima lo que cuesta más cambiar en las personas: sus modos de actuar, es decir, sus conductas.

\section{Palabras-Clave}

Praxiología Motriz; Conducta motriz; Paradigma; Educación Física.

\section{THE MOTOR CONDUCT: A NEW PARADIGM FOR THE PHYSICAL EDUCATION OF THE XXI CENTURY}

Francisco Lagardera Otero

\section{Resumo}

O texto estuda a necessidade urgente de que a Educação Física realize uma autêntica revolução copérnicana para que consiga ser capaz de desenvolver todo seu potencial pedagógico, de acordo com as expectativas e necessidades da sociedade contemporânea. $\mathrm{O}$ ser humano funciona como um todo, como um sistema inteligente, de modo que em cada decisão tomada e em cada ação que empreende todo o sistema coloca em funcionamento: a afetividade, o psiquismo, os órgãos, toda a experiência acumulada..., absolutamente todo o ser. Pierre Parlebas já desenvolveu há quatro décadas um conceito que entende ao ser humano como um sistema: a conduta motora, de modo que cada pessoa vai escrevendo sua biografia motora na medida que vai evoluindo como ser vivo. A educação física aplicando a pedagogia das condutas motoras pode ser capaz de otimizar, ou seja, de melhorar, as condutas motoras das pessoas de acordo a determinados objetivos. Esta e não outra atividade é a autêntica especificidade da educação física, um grande valor pedagógico e social, pois pode ser capaz de ajudar eficazmente a modificar de maneira magistral o que custa mais mudar nas pessoas: seus modos de atuar, alias, suas condutas.

\section{Palavras-Chave}

Praxiologia motriz (motora); Conduta motora; Paradigma; Educação Física. 


\section{INTRODUCCIÓN}

En las últimas dos décadas la educación física en España ha llevado a cabo una profunda transformación, abandonando el carácter marginal que tuvo en el sistema educativo hasta la creación de la licenciatura, y posteriormente, logrando el reconocimiento oficial y normativo de la asignatura y de su profesorado, tanto en enseñanza primaria como en secundaria y universitaria. Estos cambios han posibilitado que durante este tiempo se haya pasado de disponer de cuatro centros superiores de formación de licenciados a casi una treintena actualmente, además de otros centros de formación superior de profesores de enseñanza primaria especialistas en esta materia.

Pero a pesar de estos elocuentes avances relativos a la mejora ostensible del estatus social de la asignatura y de sus enseñantes, la formación de éstos sigue basándose en saberes dispersos e inconexos, faltos de una organización teórica coherente y de una aplicabilidad congruente, ya que se sustenta en conceptos muy poco actualizados en relación a los paradigmas científicos vigentes. A la modernización tecnológica y al avance social no le ha correspondido una revitalización de los conocimientos científicos, por esto sus procedimientos siguen siendo arcaicos.

Resulta imprescindible que la educación física se abrace definitivamente a los principios de la física cuántica, de la biología embrionaria, de las ciencias humanas y de la sistémica, para que conciba al ser humano como un sistema inteligente que reacciona como un todo, aunque solo se estimule alguna de sus partes, y lo mejor, que decida aplicar de modo resolutivo y pragmático estos ya universalmente aceptados principios de la vida (LAGARDERA; LAVEGA, 2005, p. $85)$.

En estricto sentido disciplinar considero que la educación física española está aún viviendo en la premodernidad, pues aunque en apariencia su formato se ha modernizado, sus fundamentos siguen obsoletos. Las Facultades de Educación Física no han sabido dar el giro que necesitaban de acuerdo con los avances científicos del último siglo. La formación de los futuros profesores de educación física se basa, aún hoy en Francia, en los principios concebidos en el siglo XIX (PARLEBAS, P., 2003, p. 16). Y también en España, añadimos, y en prácticamente todo el mundo.

La mayoría de universidades y profesores siguen anclados en el concepto de movimiento, claramente definido y tratado por la física mecánica, pero impreciso y superficial para explicar y comprender la acción humana, compleja y repleta de singularidades. El movimiento es la manifestación de un fenómeno vital mucho más profundo, de ahí que las consecuencias aplicadas de este enfoque se queden en las formas y en las apariencias. 
Recientemente unas admiradas colegas insistían en el apabullante consenso que sigue existiendo en torno a este concepto nuclear: "A pesar de que existan diferentes puntos de vista, la mayoría de los estudiosos están de acuerdo en que el objeto de estudio de las ciencias de la actividad física y el deporte es el cuerpo en movimiento" (LÓPEZ; CASTAÑER, 2006, p. 50). Sin embargo, y aunque la mayoría del pueblo siga viendo al rey vestido, a pesar de ir completamente desnudo, seguiremos clamando en el desierto que el rey se pasea sin ropa, por grande y hermosa que luzca su corona; es decir, constatamos una vez más que la educación física sigue desnuda.

Existen muchos colegas que pretenden dar carpetazo al cartesianismo aún imperante en el ámbito disciplinar (disociación del cuerpo y la mente), porque la experiencia educativa les muestra que el ser humano es uno y centrar la atención educativa en transmitir habilidades, no deja de ser un adiestramiento, aunque se haga de manera muy tecnológica y sofisticada. Pero no basta con criticar el dualismo cuerpomente para abrazarse a la unidad, sino que hay que utilizar los conceptos y los procedimientos que indiquen claramente que se está en esa vía, que tanto teórica como prácticamente se trabaja con la persona en su totalidad, en dirección a la unidad.

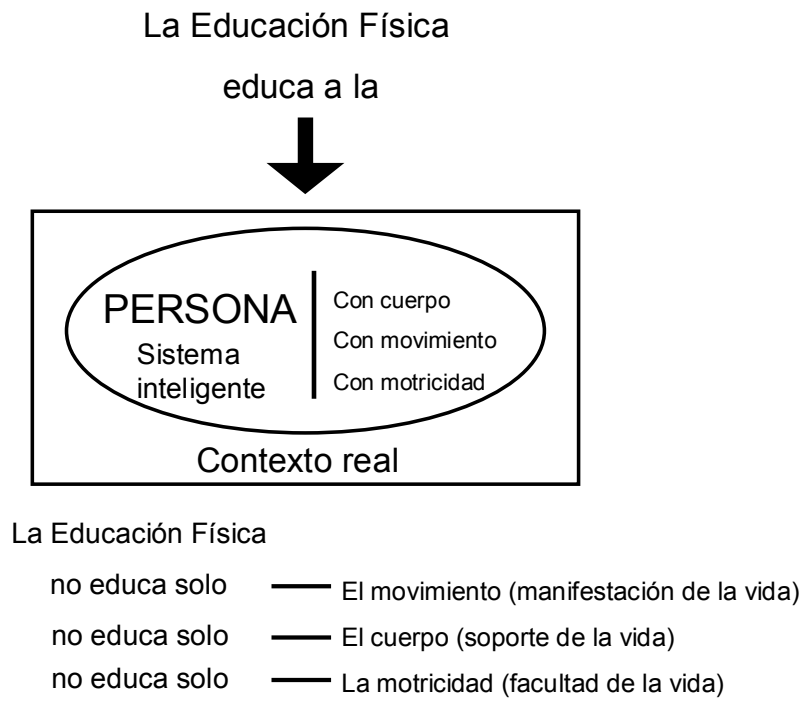

Esquema 1

No es el cuerpo el que se educa, ni el movimiento, ni la motricidad, al menos desde una perspectiva sistémica, es decir, global e interactiva, sino que es la persona el objeto central de la educación, muy especialmente de la educación física que posee un valioso potencial para educar al ser humano de un 
modo específico y original. Podemos permanecer completamente inmóviles o movernos frenéticamente, dependerá del contexto y de nuestra decisión, pero en cualquier caso se trata de una acción, motriz, si está orientada hacia la propia motricidad. Una acción motriz siempre implica a la motricidad, a un cuerpo y a muchos movimientos, siendo la persona entera, con sus afectos, miedos e ilusiones, la que la lleva a cabo.

\section{CAPITAL SOCIAL DE LA EDUCACIÓN FÍSICA Y CAMBIO DE PARADIGMA}

Del mismo modo que un capital económico aumenta las posibilidades de una persona o de una empresa para invertir en lo que considere necesario, las sociedades disponen de toda una "urdimbre de sentimientos, actitudes, normas y comportamientos que forman el capital social de una comunidad" (MARINA, 2006, p. 125) y que dan buena medida de su grado de civilización y de sus posibilidades de generar un contexto social de bienestar entre sus miembros.

La educación física tiene que cambiar de paradigma si desea convertirse en un importantísimo capital social en el siglo XXI. Centrar su atención en la persona y no en los resultados, en las habilidades, en las destrezas, en los gestos.

Un paradigma constituye aquél conjunto de verdades, axiomas, leyes y teorías que aceptadas por la comunidad científica, al menos por su sector relevante y hegemónico, son su referencia válida y normativizada para la resolución de problemas, constituyendo por tanto un marco claro y homogéneo desde donde emprender cualquier investigación. Los paradigmas funcionan hasta que el desarrollo de una nueva teoría pueda confirmarse o ser aceptada por la comunidad científica entrando en abierta confrontación con aquella, en cuyo caso la sustituye, pudiendo sin embargo complementarse con el viejo paradigma, lo que conduce a la modificación o mejora de aquél (KUHN, 1986). En el caso de la educación física, por tratarse de una pedagogía y no de una ciencia, se entiende por paradigma al conjunto de teorías y conceptos en los que se fundamenta su intervención educativa.

Conviene tener en cuenta que los peculiares rasgos que para educar posee la educación física (LAGARDERA, 2001) convierten a su potencial educativo en un auténtico tesoro, un magnífico capital social que puede ayudar de manera eficaz y ostensible a tejer esa urdimbre que requiere toda comunidad humana para seguir civilizándose y progresar en la calidad de vida de sus miembros, dado que tiene el poder de concretizar, o mejor, de hacer real de modo práctico el modelo de persona que la cultura dominante proponga como óptimo, pero para lograrlo es necesario cambiar el paradigma actualmente 
vigente, aquél que le hace prestar atención al movimiento, a las formas y manifestaciones, y no al ser que actúa y decide, a la persona, la sustancia del proceso educativo.

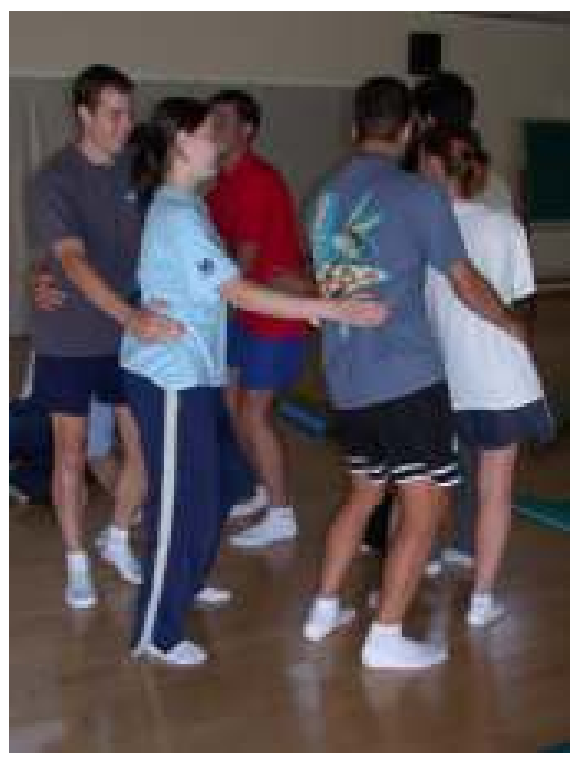

Figura 1

A todos los seres humanos les cuesta cambiar. Modificar hábitos, costumbres y gustos implica siempre un gran esfuerzo, especialmente las creencias, que se instalan en cada persona como parte de uno mismo, de un modo casi pétreo e inamovible. Esto ha llevado a muchos educadores y pensadores a considerar que para cambiar lo trascendente es la toma de conciencia, para posteriormente poder modificar los comportamientos en la línea que se considere más apropiada en relación a patrones éticos, morales, ideológicos o de salud.

Pero diariamente se comprueba que millones de personas se proponen dejar de consumir ciertos alimentos, abandonar el hábito de fumar o comenzar a realizar ejercicio físico cotidianamente, pero no lo consiguen por más que tienen conciencia clara de que ciertas costumbres les resultan perjudiciales y en cambio otras les proporcionan salud y bienestar.

Sin embargo, la educación física, al actuar directamente sobre toda la persona, ya que cuando alguien salta, camina, da giros y volteretas o baila es toda su vida la que se implica al llevar a cabo estas acciones motrices, proporciona a los alumnos con sus propuestas didácticas experiencias en las que necesariamente participa todo el ser, es decir, toda la vida de la persona queda afectada. Actualmente se sabe que no es solo la memoria del córtex cerebral la que es capaz de retener esa vivencia, sino que es todo el cuerpo 
quien la hace suya: la piel retiene las sensaciones táctiles, los pies y las piernas las sensaciones asociadas a los desplazamientos, el corazón los sentimientos y emociones, los riñones los cambios de temperatura, los huesos y músculos las sensaciones de debilidad y fortaleza..., y así sucesivamente, pues es toda la vida de modo sistémico la que interviene en cada acción motriz.

Hoy en día se puede asumir a la luz de los avances científicos que la naturaleza del ser humano es física (MOSTERÍN, 2006), aunque mediante la conciencia trascienda este mero ser físico. Una persona es un ente que tiene conciencia de sí mismo, es soma y psique a la vez. La existencia humana está integrada en un todo complejo en donde el inteligir ha constituido un proceso derivado de la evolución de su mero sentir. No se puede olvidar que la cognición es la materia prima de la inteligencia (MATURANA; VARELA, 1990) y que ésta ha sido la última en llegar a habitar el edificio que constituye la larga y compleja construcción evolutiva que es la vida humana. El ser humano en su totalidad es un ente inteligente, capaz de darse cuenta de la realidad y hacerla suya con cada acción consciente que emprende, y si esta es de carácter motor ya no cabe la disociación cuerpo-mente.

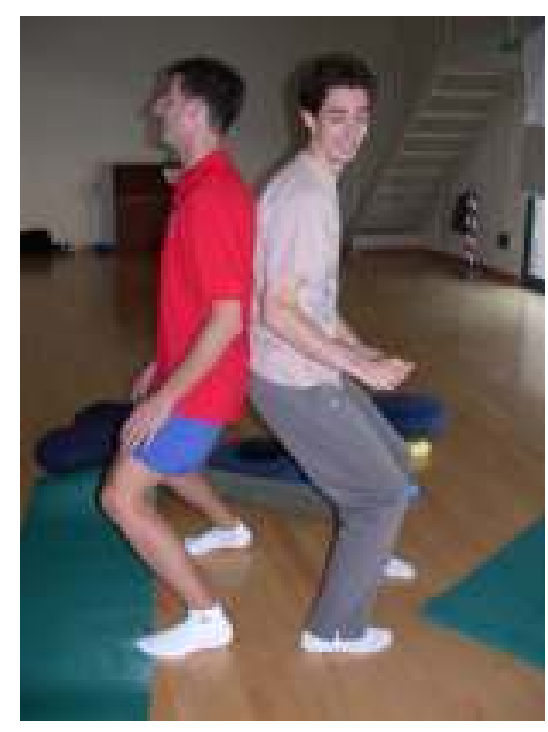

Figura 2

Para que en un inmediato futuro se pueda rentabilizar el valioso capital social de la educación física, en cuanto pedagogía que es capaz de incidir en la totalidad del ser humano mediante la inmersión de los sujetos en su propia realidad vital, se requiere situar como objeto central de la acción educativa a la persona que aprende. 
Esto implica un cambio drástico de paradigma en la educación física imperante puesto que, por una parte, es cada una de las personas que aprenden, con todo su cortejo de rasgos y singularidades, el objeto primero de interés pedagógico, por tanto conocer y estudiar a sus alumnos se convierte en la primera tarea a realizar para todo docente.

La frecuente apelación a la educación en valores, es una necesidad de la sociedad actual para dirigir a los jóvenes hacia el Gran Proyecto Ético de la Humanidad (MARINA, 2006), constituyendo la fuente primera de la que sustraer o seleccionar los objetivos educativos prioritarios para educar a las personas de acuerdo a los principios y necesidades de la sociedad, de modo que se asegure así su desarrollo y evolución favorable. De ahí que los profesores de educación física tengan la responsabilidad de obrar de modo congruente con los objetivos pedagógicos enunciados, aprendiendo a seleccionar las situaciones motrices que estimulen en sus alumnos la aparición de conductas motrices que pongan en práctica estos valores. Pero para lograrlo tienen, en primer lugar, que centrar su labor pedagógica en la persona que aprende, aceptándola como un ser único y complejo, por esto la necesidad de utilizar la noción de conducta motriz, y segundo, saber aplicar nociones básicas de Praxiología Motriz para conocer la lógica interna de cualquier tarea motriz propuesta.

Al parecer los expertos en psicología y pedagogía abogan constantemente por la necesidad de poner en práctica los comportamientos prosociales, pero parece no tenerse en cuenta que la educación física es ante todo una educación práctica, sobre el terreno, que proporciona experiencias sensitivas, vivencias de las que se impregna la totalidad del ser. ¿No vale la pena intentar este cambio de paradigma a tenor de lo mucho que se juega la sociedad en un inmediato futuro? ¿Por cuánto tiempo más va a estar la educación física limitada por la tarea de adiestrar o mejorar movimientos, habilidades y destrezas, olvidando las peculiaridades afectivas, emocionales, psíquicas y sociales de cada persona, poniendo toda su atención educativa en ayudar a cada ser humano a optimizar sus conductas motrices para que le sea más sencillo el logro del bienestar y la felicidad?

\section{CONSECUENCIAS DEL CAMBIO DE PARADIGMA}

Lo primero que conviene aclarar es que no basta con desear un cambio de paradigma, sino que asumiendo el lastre que supone la formación actual de los docentes, éstos tienen que estudiar y formarse de tal modo que les sea posible, en el menor tiempo posible, programar primero y poner en práctica más tarde un 
proceder pedagógico global que considere a cada alumno que aprende como un ser humano único y singular.

Poner a la persona que aprende como objeto central de la intervención educativa en educación física supone:

1) Aceptar que cada persona manifiesta su singularidad de modo espontáneo e irreductible cada vez que lleva a cabo cualquier tipo de acción motriz, por tanto es posible construir los perfiles del itinerario motor de cada persona mediante la observación y evaluación de los rasgos dominantes de su conducta motriz, noción clave acuñada por la Praxiología Motriz que entiende que cada persona al realizar una acción motriz la dota de matices y singularidades originales. No se trata de comparar cómo efectúa un pase cada uno de los alumnos, sino de observar, conocer y registrar el modo peculiar que tiene cada cual de pasar y a partir de este conocimiento, poder seleccionar las situaciones motrices más adecuadas para que cada una de las personas implicadas sean capaces de modificar y optimizar sus conductas motrices.

2) Aceptar que en educación física la persona aprende conocimientos procedimentales (PARLEBAS, 2001, p. 87) y que por ello requiere la implicación del protagonista en la acción educativa, que consiste en la ejecución singular de acciones motrices que constituyen o forman parte de las situaciones motrices seleccionadas por el profesor, de modo que éstas faculten la emergencia de conductas motrices que satisfagan sus intereses, que mejoren su eficacia para alcanzar logros o que le proporcionen bienestar.

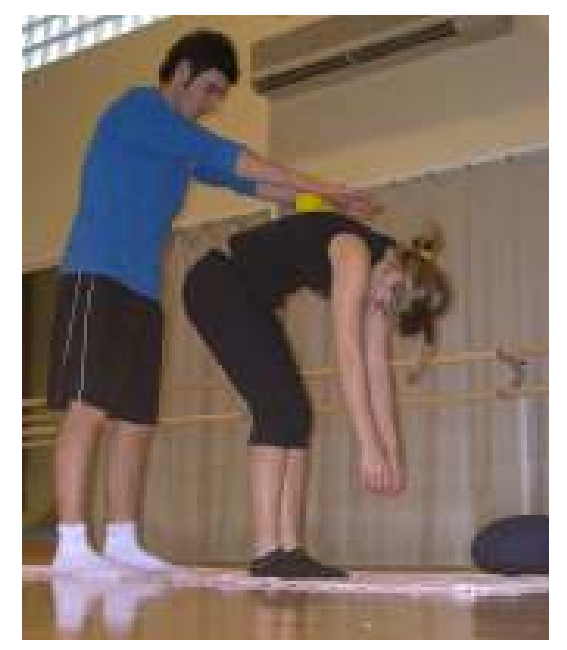

Figura 3 
Para aprender a nadar el sujeto necesita introducirse en el agua y experimentar la flotabilidad, para aprender a bailar acompasar su ritmo vital al ritmo musical con cada paso que dé o gesto que haga, para aprender a patinar requiere calzarse unos patines y comenzar a reequilibrarse con ellos en desplazamientos lentos y balbuceantes primero, para ir adquiriendo progresivamente estabilidad y seguridad, la misma implicación se necesita para manejar una pelota con las manos o los pies, para aprender a montar en bicicleta, para esquiar, para sentarse en una silla con el espinazo alineado y estirado o para caminar con armonía y equilibrio. Con el rasgo nada desdeñable de que este tipo de conocimientos procedimentales, una vez aprendidos, no se olvidan.

3) Aceptar que una vez que los profesores, la comunidad educativa o la sociedad en su conjunto, hayan determinado qué valores, qué ideales o qué tipo de personas desean educar, es decir, se hayan establecido los objetivos pedagógicos, por una parte, $\mathrm{y}$ conocidos los alumnos a los que afecta el programa, por otra, tratar que todos y cada una de las personas objeto de educación, adapten y transformen sus conductas motrices en la dirección propuesta, pero esto sí, construyendo y desarrollando programas de intervención congruentes con las directrices propuestas.

Resulta inaceptable que se trate de estimular la solidaridad practicando el baloncesto o fomentar la autoestima practicando el salto de longitud. Lamentablemente se pueden hallar aún hoy multitud de programas oficiales, y lo que es peor, actitudes y quehaceres de profesores que actúan bajo preceptos idealistas, con propuestas y actuaciones muy poco congruentes. Para cada uno de los objetivos propuestos en los programas se tienen que seleccionar, crear o elegir aquellas situaciones motrices que, de acuerdo a los rasgos de su lógica interna, hagan emerger las conductas motrices deseadas, lo que implica que los docentes tienen que conocer la lógica interna de todas y cada una de las situaciones motrices planteadas.

Asumir estos tres preceptos supone poner en cuestión el paradigma actualmente vigente en educación física, de modo que la idea de movimiento deje de ser el ojo por el que esta pedagogía observe la realidad educativa, ya que su visión se proyecta fuera de la persona que aprende, aunque se siga utilizando y aplicando de modo restringido para comprender o resolver problemas biomecánicos que tienen que ver con la práctica motriz pero que no son la persona que aprende; y al mismo tiempo, para obrar la transformación necesaria que supone este cambio de paradigma, los profesores tienen que comenzar a 
estudiar y trabajar orientando sus esfuerzos en otra dirección, lo que necesariamente tiene consecuencias en el estado actual de las cosas ya que:

- La pedagogía de las conductas motrices se erige en el modo más adecuado, original y específico de llevar a cabo programas renovados en educación física, de tal modo que los esfuerzos docentes se dirijan hacia el conocimiento y observación sistemática de los comportamientos motores de los alumnos para que sean interpretados adecuadamente como conductas motrices singulares, siendo así posible evaluar constantemente el proceso de transformación llevado a cabo por cada uno de ellos en la dirección de los objetivos planteados como conductas motrices óptimas (LAGARDERA; LAVEGA, 2005). Es decir, a través de su acción pedagógica la educación física puede ayudar a las personas a optimizar sus conductas motrices, de modo que actuando así contribuya de modo práctico y eficaz a mejorar la calidad y bienestar de sus vidas.

Esto quiere decir que los educadores tienen que aprender a catalogar y describir conductas motrices, al menos las consideradas óptimas a tenor de sus objetivos educativos, y a establecer los métodos para observar y registrar la aparición de éstas en el itinerario motor de cada uno de sus alumnos, como una vía accesible y posibilista a un tipo de educación física personalizada.

口 Resulta estrictamente necesario que exista una clara relación de congruencia entre los propósitos educativos establecidos por la comunidad educativa y la lógica interna de las situaciones motrices programadas como tareas didácticas. No existen unas prácticas motrices mejores que otras sino que cada una de ellas responde a un orden interno o estructura que obliga a los participantes a llevar a cabo unas determinadas acciones motrices y no otras. Es decir, para un determinado valor, sea éste la solidaridad, la cooperación, la competitividad o la generosidad, tienen que programarse situaciones motrices en las que los protagonistas tengan necesariamente que poner en acción conductas motrices congruentes con este valor.

No resulta admisible que el atletismo, el fútbol, la danza clásica o los malabarismos, pongamos por ejemplo, constituyan tareas motrices elegidas en función de criterios sociales, culturales, ideológicos, históricos o económicos, por muy importantes que sean las razones de todo tipo que avalen esta elección, sino que tienen que ser los rasgos dominantes de su lógica interna, por pertenecer a la acción motriz (LAGARDERA; LAVEGA, 2003), los que guarden una relación de congruencia con los objetivos 
perseguidos, ya que esta es la vía pertinente que dispone la educación física para optimizar las conductas motrices de las personas.

$\underline{\text { Para aplicar el nuevo paradigma el profesor de educación física tiene que: }}$

1. Aprender a catalogar y describir conductas motrices a partir de la observación de los comportamientos motores de sus alumnos.

2. Aprender a dilucidar y conocer la lógica interna de todas las situaciones motrices que plantee a sus alumnos. Es decir, tener conocimientos aplicados de Praxiología Motriz.

Se acaba de publicar recientemente un documento sumamente importante para salvaguardar la comunidad de la vida en el planeta: La carta de la Tierra en acción (2006), que desarrolla un gran proyecto internacional basado en dieciseis principios éticos, pues bien, todos estos ideales pueden aplicarse desde muchas facetas de la vida, pero la educación física puede y debe ponerlos en práctica a partir de situaciones motrices cuya lógica interna promuevan conductas motrices en congruencia con este maravilloso proyecto. Pero para esto "conviene efectuar una renovación profunda, una verdadera revolución copernicana, para poner a la acción motriz en el centro de la reflexión y de la formación. Es necesario un cambio de paradigma” (PARLEBAS, 2003, p. 17) que afecte a los programas de formación de los profesores de educación física, ya que es la Praxiología Motriz la base teórica requerida para que los futuros profesores sean capaces de conocer y desvelar la lógica interna de cualquier situación motriz, sea esta elegida o recuperada de la tradición, de un museo arqueológico o creación original del propio docente.

Sin minimizar la importancia que siguen manteniendo los estudios básicos en anatomía, biomecánica, fisiología, psicología o sociología, es el conocimiento profundo de la acción motriz lo que capacita a los especialistas en educación física de formación coherente con su dedicación pedagógica.

\section{DOMINIOS DE ACCIÓN MOTRIZ Y PROGRAMAS RENOVADOS EN EDUCACIÓN FÍSICA}

Existen millones de situaciones motrices susceptibles de ser elegidas para configurar los programas de intervención pedagógica en educación física, provengan originariamente de cualquiera de las fuentes de la cultura humana posibles: aquellos que provienen o se derivan del propio cuerpo, técnicas corporales según Marcel Mauss (1979), de los juegos tradicionales o de los deportes; no se puede afirmar que unas 
sean más educativas, prioritarias o importantes que otras.

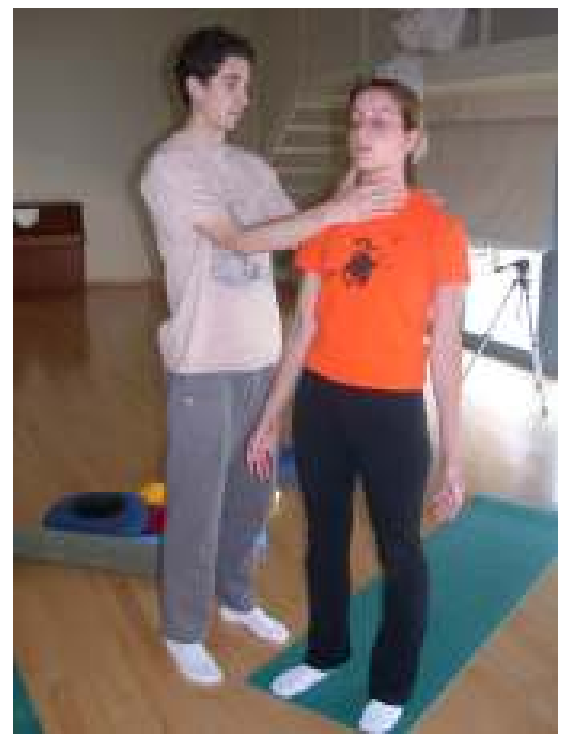

Figura 4

Resulta trascendente tener en cuenta, aunque resulte reiterativo mencionarlo de nuevo, que cada práctica motriz posee una determinada lógica interna y es el conocimiento de ésta y su complementariedad y congruencia con los objetivos perseguidos, lo que debe inducir al docente para seleccionarlas y proponerlas a sus alumnos.

En hemerotecas, bibliotecas, pinacotecas e incluso museos arqueológicos, se pueden hallar multitud de indicios, descripciones, crónicas e incluso testimonios muy completos de manifestaciones motrices que nos han precedido cientos y miles de años, dado que la historia de los pueblos y sus culturas son fiel reflejo de una manifestación tan humana, social y culturalmente, como lo son los ejercicios físicos y las prácticas motrices en general. Todas estas manifestaciones son susceptibles de ser elegidas como tareas motrices en las clases de educación física, como también lo pueden ser los millones de propuestas que aún no han sido creadas por la especie humana pero lo pueden ser en cualquier momento. No es un problema de cantidad, sino de pertinencia, coherencia y congruencia; de ahí que sea de capital importancia el conocimiento de los dominios de acción motriz por parte del docente en educación física.

Por dominios de acción motriz se entiende el campo en el que las prácticas corporales son consideradas homogéneas respecto a criterios pertinentes y precisos de la acción motriz... Es pues, una clase de actividades ludomotrices, institucionalizadas o no, que tienen en común algunas características importantes de su lógica interna, como por ejemplo la incertidumbre que procede del entorno o la interacción con un adversario (PARLEBAS, 2001, p. 161). 
Cuando se hace referencia a dominios de acción motriz se le asocia de inmediato la clasificación de las prácticas motrices y como ésta las agrupa en clases o familias que ostentan algunos rasgos comunes de su lógica interna. Hay que volver, una y otra vez, a este concepto central en toda la teoría de la acción motriz, puesto que si se conciben los juegos, deportes y cualquier situación motriz como un sistema praxiológico, su orden se mantiene en la medida que lo haga su lógica interna.

Desde el planteamiento más abstracto y genérico, como lo puedan ser los programas de educación física confeccionados para el ámbito de un determinado Estado o región, como los recientemente confeccionados en Aragón (LARRAZ, 2004).

Hasta el programa de intervención más singular aplicado por un docente para un determinado grupo de personas, la clasificación de las prácticas motrices y su organización en dominios de acción motriz es un recurso imprescindible para obrar con pertinencia, ya que se trata de una clasificación realizada en base a rasgos constitutivos de la acción motriz y no a otros criterios, como puedan ser los históricos, geográficos, económicos o sociológicos.

La referencia constante a los dominios de acción motriz es también una decisión coherente, dado que si se parte de la teoría sistémica hay que concebir las prácticas motrices como sistemas praxiológicos y así mismo, al participante, como un sistema inteligente susceptible de llevar a cabo conductas motrices, noción sistémica por excelencia.

\section{Avance científico y epistemológico de la Educación Física:}

a) Avanzar con PERTINENCIA: utilizando los dominios de acción motriz para la selección de situaciones didácticas.

b) Avanzar con COHERENCIA:

* la persona (alumno) concebida como un sistema inteligente.

* las prácticas motrices concebidas como sistemas praxiológicos.

* la conducta motriz (constructo sistémico creado para ser aplicado a la educación física) es objeto de optimización educativa.

c) Avanzar con CONGRUENCIA: la lógica interna de las situaciones motrices programadas provoca los efectos pedagógicos esperados por los objetivos educativos propuestos. 
Finalmente, los dominios de acción motriz permiten al pedagogo obrar con congruencia, puesto que es un conocimiento necesario para seleccionar y diseñar situaciones motrices que desencadenen los procesos prácticos que desean llevar a cabo los objetivos propuestos, ya que los diferentes dominios están organizados de modo que se puede conocer la tendencia dominante de la lógica interna de cada situación elegida.

Por todo esto, cualquier programa renovado de educación física que desee elaborarse desde el paradigma de la acción motriz, campo susceptible de generar un área de conocimiento original y específica en el ámbito actual de la ciencia, tal y como lo ha hecho recientemente la Comunidad Autónoma de Aragón para la educación física en primaria, se tienen que aplicar los principios siguientes:

a) Abandonar el planteamiento clásico en términos de aptitudes físicas y substituirlo por un planteamiento en relación al contexto de la acción motriz, es decir, tener en cuenta "las relaciones que el individuo establece con su entorno de acción. No es necesario separar al sujeto de su contexto de intervención, y menos aún para la descripción e identificación de las actividades" (PARLEBAS, 2003, p. 3). Por esto conviene considerar las prácticas elegidas como situaciones motrices, noción que engloba a la vez al actor y a su contexto, y como éstas, de acuerdo a su lógica interna, hacen emerger o provocan entre los participantes determinadas conductas motrices, el eje central, no lo olvidemos, del nuevo paradigma en educación física: la persona como agente capaz de llevar a cabo la optimización de sus conductas motrices, en este caso, ayudado por la conducción y guía de un docente innovador y formado.

b) "Identificar cada situación motriz por su significación relacional y humana, tomando en cuenta la vivencia global suscitada por la acción emprendida" (PARLEBAS, 2003, p. 3 ). Lo cual implica tener en cuenta si se trata de una situación psicomotriz, comotriz o sociomotriz; si consiste en un duelo entre individuos o entre equipos, de una competición concurrente o de un concurso, de una situación motriz adaptativa, expresiva, cooperativa y/o de cualquier otro rasgo dominante en la acción motriz emprendida, puesto que cada una de estas situaciones desencadena en los participantes diferentes emociones y vivencias, dado que suscita la aparición de conductas motrices muy diferenciadas. 
c) "Identificar de manera precisa los rasgos de la lógica interna que caracteriza a las acciones motrices suscitadas por la práctica motriz elegida" (PARLEBAS, 2003, p. 4), puesto que el único modo de ayudar a los alumnos a optimizar sus conductas motrices es plantearles o sugerirles situaciones motrices cuya lógica interna les impulse o estimule a hacerlo, de modo que ante la dificultad de un alumno o grupo de ellos para llevar a cabo, pongamos por ejemplo las conductas motrices de solidaridad y ayuda, el docente tendrá que plantear situaciones motrices que pongan en juego la solidaridad y la necesidad de ayudarse para realizarlas. No en vano, a partir de un conocimiento aplicado de la Praxiología Motriz, ciencia de la acción motriz, cualquier valor, precepto moral y objetivo comportamental, puede ser puesto en práctica a partir de diseñar situaciones motrices congruentes con esos propósitos.

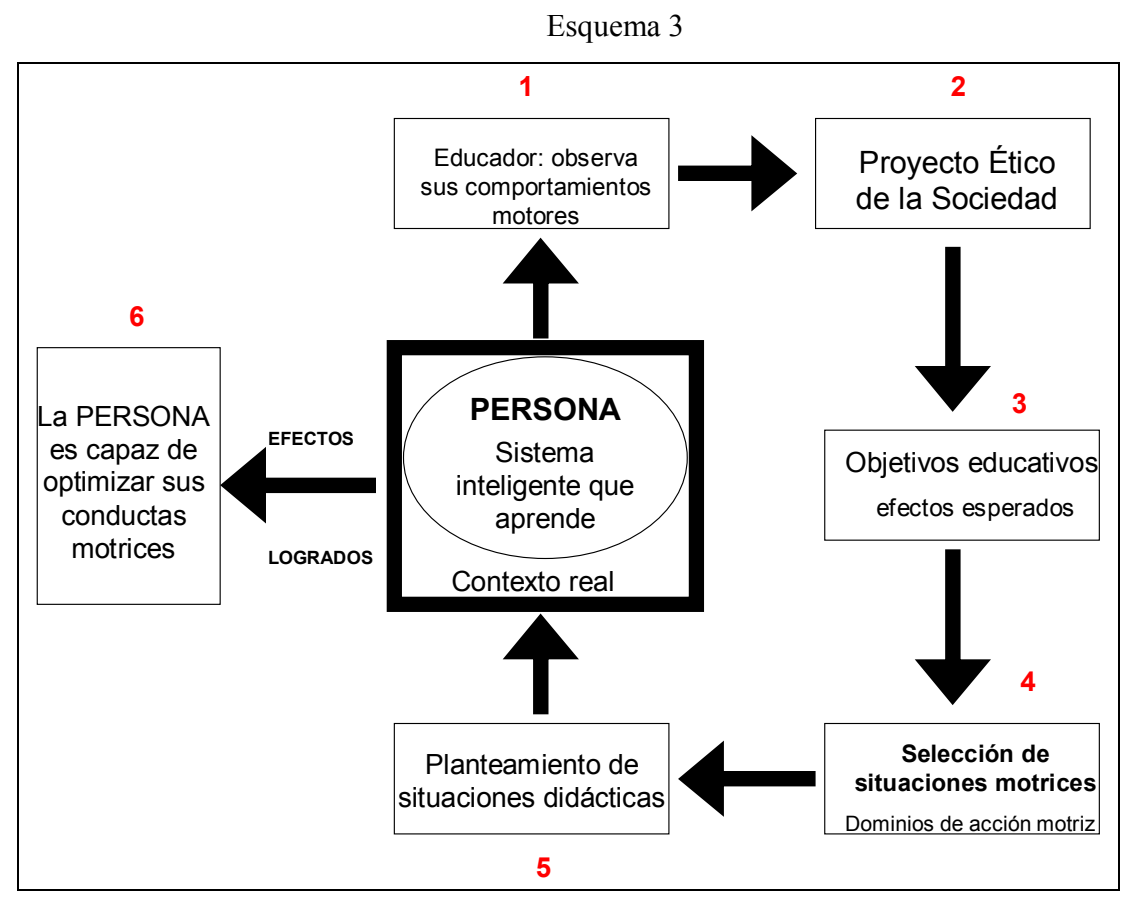

\section{POR UN NUEVO PARADIGMA EN EDUCACIÓN FÍSICA}

Se puede concluir que la educación física requiere hoy de modo perentorio, si pretende adaptarse a las innovaciones científicas y al desarrollo social imperante, modificar sustancialmente el objeto de su intervención pedagógica, abandonando el movimiento como concepto de referencia para ubicar a la persona como objeto central de educación; sustituyendo las nociones de aptitud, capacidad y habilidad que ponen su atención en un rendimiento o meta abstracto por el de conducta motriz, que concibe al sujeto que aprende como un ser global, inteligente, único y singular. 
Pero para que esto sea posible resulta necesario modificar los programas de formación de profesores. Es imprescindible que, tanto en los centros superiores de formación de profesores y licenciados, así como en los foros científicos de este ámbito, se critique la teoría de la acción motriz y se reflexione en torno a su pertinencia, pero especialmente, se considere la necesidad de consolidar el área de conocimiento de la acción motriz como aquel conjunto de conceptos originales y procedimientos específicos que capacitan a los especialistas para analizar, conocer, seleccionar y evaluar las situaciones motrices cuya lógica interna sea congruente con la intencionalidad de sus objetivos educativos, es decir, con el proyecto de persona que se desea construir, en este caso de modo práctico, tratando de optimizar sus conductas motrices.

Sin menoscabo del interés suscitado por los estudios e investigaciones que sobre las prácticas motrices vienen llevando a cabo otras disciplinas científicas, como pueda ser el caso de la sociología del deporte, la fisiología del esfuerzo o la biomecánica deportiva; la educación física, por constituir un procedimiento pedagógico original y específico, requiere fundamentar su intervención en una disciplina científica que ha sido creada para conocer las consecuencias prácticas de cualquier situación motriz considerada como un sistema praxiológico, este es el caso de la Praxiología Motriz, llamada a constituir el soporte teórico que nutra la formación cualificada de los educadores físicos.

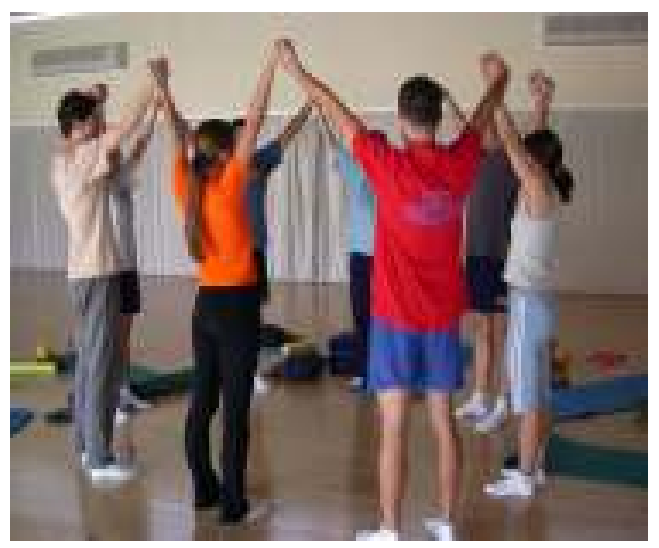

Figura 5

No resulta una actitud científica ni ética tolerable, marginar o ignorar este conocimiento, que Parlebas viene proponiendo y divulgando desde hace más de treinta años y que es imprescindible para la incorporación del nuevo paradigma aquí expuesto. Lo único que cabe es llevar a cabo todas las críticas públicas que puedan elaborarse a estas proposiciones y someterlas a un análisis y reflexión concienzudo y sistemático, como paso previo a su divulgación e instauración dentro del tejido social que forma la comunidad educativa de profesores de educación física. 
Galileo Galilei que había apoyado y defendido en sus publicaciones las tesis revolucionarias de Copérnico, fue obligado a abjurar ante el tribunal de la Congregación del Santo Oficio de estas posiciones, aunque a pesar de esta enorme presión fue capaz de pronunciar la célebre frase: $y$ sin embargo se mueve..., como muestra de que el conocimiento crítico y fundamentado en la ciencia se impone con el transcurrir del tiempo, pese a los intereses del poder hegemónico constituido, aún a costa del destierro o el descrédito de su mentor. Confiemos en que la educación física haga posible su transformación y alcance la modernidad, sustituyendo el paradigma ahora dominante sin necesidad de convertir a la conducta motriz y a sus promotores en abjurados de si mismos.

\section{REFERENCIAS}

BLAZE, P.; VILELA, M.; ROERINK, A. (Ed.) La carta de la tierra en acción. Hacia un mundo sostenible. Ámsterdam: KIT Publishers; 2006

KUHN,T.S. La estructura de las revoluciones cientificas. Madrid: FCE., 1986

LAGARDERA, F. Por una educación física integral para el siglo XXI: Revista Tándem, Barcelona, n. 1,2001

LAGARDERA F.; LAVEGA, P. Introducción a la praxiología motriz. Barcelona: Paidotribo, 2003

. La educación física como pedagogía de las conductas motrices Revista Tándem, Barcelona: n. 18,2005

LARRAZ, A. Los dominios de acción motriz como base de los diseños curriculares en educación física: el caso de la comunidad autónoma de Aragón en educación primaria In: LAGARDERA F.; LAVEGA, P. (Ed.). La ciencia de la acción motriz. Lleida: Edicions de la Universitat de Lleida, 2004

LÓPEZ, C.; CASTAÑER, M. El cuerpo máquina en las aulas de educación física Revista Tándem, Barcelona, n. 21, 2006

MARINA, J. A. Aprender a convivir. Barcelona: Ariel, 2006

MATURANA, H.; VARELA, F. El árbol del conocimiento. Barcelona: Debate, 1990

MAUSS, M. Sociología y antropología. Madrid: Tecnos, 1979

MOSTERÍN, J. La naturaleza humana. Madrid: Espasa Calpe, 2006

PARLEBAS, P. Juegos, deporte y sociedad: léxico de praxiología motriz. Barcelona: Paidotribo, 2001

PARLEBAS, P. Un nuevo paradigma en educación física: los dominios de acción motriz: CONGRESO FIEP., Caceres, 2003 


\section{Referência do artigo:}

\section{ABNT}

OTERO, F. L. La conducta motriz: un nuevo paradigma para la educación física Del siglo XXI. Conexões, v.5, n. 2, p. 1-18, 2007.

\section{APA}

Otero, F. L. (2007). La conducta motriz: un nuevo paradigma para la educación física Del siglo XXI. Conexões, 5(2), 1-18.

\section{VANCOUVER}

Otero FL. La conducta motriz: un nuevo paradigma para la educación física Del siglo XXI. Conexões, 2007, 5(2): 1-18. 